\title{
Call and Vocabulary Acquisition (Theoretical Perspective)
}

\author{
ManalAwad Mohammed Elwakeil \\ Sudan University of Science and Technology, Graduate College, College of Languages \\ *Corresponding Author: ManalAwad Mohammed Elwakeil, Sudan University of Science and \\ Technology, Graduate College, College of Languages.

\begin{abstract}
Computers are not only for saving data and playing games. Computers have proven to have a more crucial role in society as they play as a mean for learning. Recent technological advancements have created the possibility of new ways of teaching and learning. The passive teacher-centered learning approach has now shifted its focus towards encouraging students to actively participate in their learning process. Crystal (1997) explained that in the past, foreign language teaching depended on teaching techniques and teaching efficiency as teaching was active while learning was passive, while the active role is played by the learner. Recently, developing a high learning efficiency using technology has been of main interest for many learning institutions. Nevertheless, taking full advantage of this potential requires considering the teaching/learning procedure in new ways as well as to master the technology itself. Today computers play a crucial role where they function as 'an added tool or resource, as a model or a real-world phenomenon or system, and as a training environment to prepare users for real-world tasks and experiences' (Pennington 1996: 11).
\end{abstract}

Keywords: CALL, computers, technological advancement, saving data, real world phenomenon

\section{INTRODUCTION}

Computers Assisted Language Learning (CALL), through its progression, followed a logical development that combines non-stop advances in technology to persistent shifts in the research of language learning and pedagogy (Wright, 2005). While advancements are being achieved in technology, research on impact of the use of computer in second language learning always shows positive evidences in the field (Hergesheimer and Tower, 2004).According to Moras (2001) CALL programs have been used since the 1960s till now. The 55-year period can be generally divided into three main stages: behaviorist (CALL), communicative CALL, and integrative CALL (Warschauer\& Healey, 1998).

Vocabulary has been the yardstick by which linguists; education experts and psychologists measured the size and effect of vocabulary right at the beginning of the $20^{\text {th }}$ century. At the beginning of the 20th century in many experiments: studies of human learning, reading and writing ability, attention, memory, and emotions. However, in the middle of the last century, linguists' interest in exploring of vocabulary declined. Chomsky's conception of generative grammar redirected linguistic research away from vocabulary toward grammar, and "excessive interest in words was followed by excessive neglect" (Miller, 1996, p. 16). Until the 1980s, teaching and learning vocabulary was not considered as important as mastering grammar, pronunciation, reading, or writing (Richards, 1976). In1980, Meara called vocabulary acquisition a neglected aspect of language learning and stated that vocabulary acquisition research at that time had been a theoretical and unsystematic.

It is the experience of most language teachers that the single, biggest component of any language course is vocabulary. No matter how well the student learns grammar, no matter how successfully the sounds of L2 are mastered, without words to express a wide range of meanings, communication in an L2 just cannot happen in any meaningful way. And yet vocabulary often seems to be the least systematized and the least well catered for of all the aspects of learning a foreign language. The purpose of this paper is to look at what we do know about the vocabulary of a language like English and to reflect on how this has been applied in language teaching.

In recent years, however, there has been a revival of interest in words. Many second language acquisition researchers argue nowadays that learning vocabulary is perhaps the most challenging aspect of becoming proficient in a second or a foreign language because of the sheer enormity of the 
task (Meara, 1995; Nation, 2001; Schmitt, 2010). Language is often compared with a building: the structure of the building is grammar, and words are the bricks in the structure. Both are necessary and important, but the number of bricks exceeds the number of the structural elements, which is why "no linguist today would seriously contest the fact that, quantitatively, vocabulary dominates in the language field and that vocabulary acquisition is the main obstacle to language acquisition" (Ma, 2009 , p. 21). Lack of vocabulary often prevents students from becoming proficient L2 (second language) readers and writers and from communicating in L2 effectively, which is why it is the most frequently reported problem for second language learners, and students in academic programs often express a desire for more vocabulary instruction (Folse, 2004). The process of L2 vocabulary acquisition begins from the very first meeting with a second language and lasts long after all the other aspects of the language have been learned, and understanding of this process is still limited. As Schmitt (1998) argued, "the mechanics of vocabulary acquisition is one of the most intriguing puzzles in second language acquisition" (p. 281).

\section{Size OF Vocabulary ReQuired by SeCONd LANGUAGE LEARNer}

As many as 80 years ago Ogden (1937) argued that 850 words could allow students to express millions of ideas. Although this number of words might be enough for expressing some ideas in a very simplified way, it is hardly enough for comprehension of a native speaker's response. Recent research states that a learner must know many more words for comprehension of written or spoken discourse. Laufer (1989) suggested that for reading comprehension, a learner must know around 95\% of the lexical items in a text to successfully guess the rest of the words. Bonk (2000) found that the same $95 \%$ of the words enables the majority of participants to achieve good comprehension of listening passages. However, Hu and Nation (2000) insisted that knowledge of $98-99 \%$ of the words is necessary, especially for written discourse. To count how many words a learner needs to know to understand $95 \%$ or $98 \%$ of discourse, we need to know how many words make up $100 \%$ - the number of words that native speakers know. Nation (2006) argues that most well conducted studies estimate the vocabulary size of an educated English native speaker as 17,000-20,000 word families, but L2 learners do not 6,000-9,000 word families (Table 1.1). The numbers in this table present not separate words but word families. A word family is a group of words that includes a base word, its inflected forms, and derived forms of the word (Nation \&Waring, 1997), for example, nation, nations, national, nationally, nationalism, international, internationalism, internationalization, and so on.

\section{WORDS}

Learners are apt to become very nervous and less confident if their tutors kept reminding them that they will have to learn thousand of English word should they seek to improve and widen their vocabulary. How can language teachers and learners approach this vast, seemingly endless store of language and make sense of it? To even attempt to do so, we need satisfying answers to the following questions:

1) 1 How is the vocabulary composed? What sorts of elements does itcontain?

2) 2 Is the vocabulary of a language organized or is it just a gigantic list ofitems, every one unique?

3) 3 If it is organized, can we use its structuring principles in languageteaching in a way similar to the way we utilize the regularity andorganization of grammatical structure?

4) 4 How can anything so vast as the vocabulary of a language, particularly asecond language, or even a relatively small part of it, be acquired by thehuman mind, stored, and made retrievable when required?

\section{WORD-FORMATION}

When we speak of the vocabulary of a language we are speaking primarily, but not exclusively, of the words of that language. For our purposes here, it is most convenient to think of words as freestanding items of language that have meaning. If we take the English word 'eating', we can see that it is freestanding in itself, and that within it has another potentially freestanding element 'eat', independently meaningful from the second element '-ing', which is meaningful but bound, that is, not freestanding. There is an English word 'eat', but there is no English word '-ing'. The two meaningful parts of 'eating' are called morphemes; therefore we can say that a word must consist of at least one potentially freestanding morpheme. Some words may consist of several morphemes: 'deformed' consists of three- 'de-form-ed' -only 'form' is a word in its own right. However 'wastepaper-basket' consists of three morphemes which at the same time are capable of being three freestanding words in 
other contexts. From this it is clear that when we talk of learning words in a language sometimes we mean either single morphemes or roots, such as 'laugh', 'make', 'box', and 'window' which cannot be further subdivided, or roots with bound morphemes attached either at the beginning as prefixes or at the end as suffixes, such as 're-make' and 'laughter' (derived words), and sometimes we mean items that consist of more than one root but which have a single identity in that they name a single thing or concept, such as 'make-believe', 'window-dressing', and 'jack-in-the-box' (compound words). For the fullest account of English word-formation processes, see Bauer (1983).Recognizing the composition of words is important; the learner can go a long way towards deciphering new words if he or she can see familiar morphemes within them.

Sometimes, recognizing morphemes is not so easy. When morphemes combine to form words, sound changes and/or spelling changes can disguise them, making their presence less obvious to the untrained ear or eye. 'Reduce' changes its vowel sound to 'reduction' when it becomes a noun; 'dry' and 'dried' have the same vowel sound but the spelling changes. Irregular verb-forms are another example of this: 'sang' must be related to 'sing' and 'sung', while 'went' seems quite unconnected with 'go' or 'gone'. 'Beauty' changes its spelling in 'beautiful'. Sometimes such changes are recurrent: the $l k l$ sound in 'electric' becomes $I s /$ in 'electricity'; the same pattern holds good for 'authentic' 'authenticity'; 'domestic' 'domesticity', and 'public' 'publicity . The stress change from the adjective 'perfect' to the verb 'perfect' is typical of a whole group of stress changing words (e.g. 'an object' 'to object'; 'a decrease' 'to decrease'). Where regularities of this kind can be observed, they can be capitalized upon by teachers and learners tackling the problems of word recognition in written and spoken contexts.

Word families can be of different sizes, but the most frequent stems can take a greater range of affixes, and as a result have bigger families. Nation (2006) shows that in English the most frequent 1,000 word families consist of about six members, and then the size of less frequent word families decreases to about three members per family at the 9,000-frequency level. Schmitt (2010) calculated that a vocabulary of 6,000 word families requires knowing about 28,000 individual words and emphasized that whereas some members of a word family can be transparently related and easy to guess, L2 learners may have trouble with less-transparent members. Acquisition of such a large number of words is "one of the greatest hurdles facing learners in acquiring English" (Schmitt, 2010, p. 332).

To choose what vocabulary to teach in a foreign language course, we need to know what the most common words are. Frequency is one of the most important characteristics affecting acquisition and use of vocabulary. In vocabulary teaching and research, lexis is often divided into 1,000 frequency band levels. A relatively small5number of the most frequent words cover the vast majority of language, and such words are most likely to be met in discourse. The most frequent 1,000 word families make up about $70-75 \%$ of a written text, and 2,000 word families allow understanding of about $80 \%$ (Nation, 2001). As a result, both native speakers and L2 learners acquire more frequent vocabulary before less frequent words.

Compared with English, in Russian, the number of words in a word family is higher than in English because it is a highly in flexional language and the number of affixes is very high. Patrick's (1989) list of the most important suffixes includes more than 80 items, and the list of the most often used prefixes consists of 23 items. In Russian, there are also agglutinative compounds containing several word roots. As a result, the number of word family members is rarely fewer than 5 and often exceeds 15 (Patrick, 1989). For native speakers of Russian it makes the process of acquisition of new words easier because they can understand the meaning of affixes and identify the common roots. For American learners of Russian, especially at the beginning level of study, this task is much more difficult not only because of the number of affixes, but also because multiple vowel and consonant variations, insertions, and deletions that make the process of root recognition problematic. Thus, knowing one word family member does not imply being able to guess other related members. Even acquisition of only the most frequent members of the most frequent word families presents a considerable difficulty for learners of Russian.

\subsection{What is Involved in Knowing a Word?}

A well-known psycholinguist George A. Miller (1995) argued that for each word it is necessary to know "its own sound, its own spelling, its own meaning, its own role, its own use, its own history" (p. 5). There are a number of qualities that may be included in the definition of knowing a word. Nation's 
(2001) comprehensive description of the qualities is presented in Table 1.2. The number of components of the information about a word form and meaning given in the table proves that it is a very challenging task to acquire complete knowledge of a word; the process of acquisition of all the word features may be very long and require multiple exposures to words.

The initial stage is to connect the word form with one meaning and fix the connection in the mind. The nature of the process of vocabulary acquisition is incremental, and other aspects of word knowledge (other meanings, usage, collocations and associations) will be acquired later over many language experiences (Schmitt, 2005). Even if we consider only the first step of the process of vocabulary acquisition, that is, knowing the meaning and the form of a word and connecting the two together, the number of words necessary for adequate comprehension of text-based reading or speechis very high. It is hardly possible just to pick up an adequate number of words from reading or communication tasks without specific focus on vocabulary acquisition. It has been argued that teaching of 3,000 or so high frequency words should be an immediate high priority for language instructors (Nation \&Waring, 1997); following this first stage, students need to master vocabulary learning strategies, which help them to continue increasing their vocabulary size. Many researchers (Judd, 1978; Nation, 2001; Schmitt, 2008) argue for a proactive approach, vocabulary expansion, which requires contributions from four stakeholders: researchers, textbook writers, teachers, and students. Strong and active contributions from all members of this learning partnership is necessary, but if students do not become active learners, they are unlikely to acquire a reasonable vocabulary size, no matter how good their textbooks or the level of instruction can be.

\begin{tabular}{|l|l|l|l|}
\hline Form & Spoken & $\mathbf{R}$ & What does the word sound like? \\
& & $\mathbf{P}$ & How is the word pronounced? \\
\hline & Written & $\mathbf{R}$ & What does the word look like? \\
& & $\mathbf{P}$ & How is the word written or spelled? \\
\hline & Word parts & $\mathbf{R}$ & What parts are recognizable in this word? \\
& & $\mathbf{P}$ & What word parts are needed to express this meaning? \\
\hline Meaning & Form and & $\mathbf{R}$ & What meaning does this word form signal? \\
& meaning & $\mathbf{P}$ & What word form can be used to express this meaning? \\
\hline & Concept and & $\mathbf{R}$ & What is included in the concept? \\
& referents & $\mathbf{P}$ & What items can the concept refer to? \\
\hline & Association & $\mathbf{R}$ & What other words does this make us think of? \\
& & $\mathbf{P}$ & What other words could we use instead of this one? \\
\hline Use & Grammatical & $\mathbf{R}$ & In what patterns does this word occur? \\
& Functions & $\mathbf{P}$ & In what patterns must we use this word? \\
\hline & Collocations & $\mathbf{R}$ & What words or types of words occur with this one? \\
& & $\mathbf{P}$ & What words or types of words must we use with this one? \\
\hline & Constraint & $\mathbf{R}$ & Where, when, and how often would we expect to meet this word? \\
& on use & $\mathbf{P}$ & Where, when, and how often can we use this word? \\
\hline
\end{tabular}

Note: $R$ = receptive knowledge, $P=$ productive knowledge

\subsection{How Words are Formed?}

Studying how words are formed offers one way of classifying vocabulary for teaching and learning purposes, for example, presenting together words that are alike in structure, though not necessarily in meaning, such as derived adjectives ending in '-al' (e.g. 'brutal', 'frontal', and 'horizontal').This is not, of course, the only way of organizing vocabulary for teaching but it is undoubtedly useful as an aid to memorizing words in some cases, especially where small, manageable sets of words with morphemic similarities can be isolated. Most teachers already do this with irregular verbs that follow a set pattern, for example, those that have II/,/re/, /AI in their three main parts (e.g. 'drink', 'drank', 'drunk'; 'ring', 'rang', 'rung'; 'sink', 'sank', 'sunk') but the same could be done, for example, with those adjectives occurring with the relatively infrequent prefix 'a-',meaning 'an absence of ... ',as in 'asocial', 'apolitical', 'asexual', 'amoral', and the element of shared meaning involved in these words, or any other recurring pattern.

One is simply to consider them as part of the rule-systems of the language, and to describe them for learners in the way that we describe and explain grammatical rules or pronunciation rules. But we can also look at word formation as a resource in the language, something the learner should be allowed to experiment with and use strategically. We might consider, for example, isolating a small group of highly productive prefixes or suffixes and encouraging learners to create 'new' words. Some of their 
creations will probably be words that already exist in the language, and some will be non-established words. This latter group need not be jettisoned, but can be explored for literary value, humorous potential, or simply for filling 'gaps' in the language (see 2.3). English, for example, is only just beginning to use a compound equivalent to the well-established Swedish compound adjective 'miljoviinlig' ('miljo-viinlig'), literally 'environment-friendly', for products and processes that do not damage the environment, up till recently a concept only expressible as a clause in English. Creative word-formation can also be seen as a communicative strategy, for supplying formations when the right word cannot be found. Possible ways of exploiting word-formation will be examined and evaluated in Section Two of this book.

\subsection{Multi-Word Units}

So far we have talked of only three types of unit in the vocabulary of a language like English: basic roots (e.g. 'plate'), derived words (e.g. 'defrost'), and compounds (e.g. 'lampshade'), but when we look at written and spoken texts in English, we see a large number of recurring fixed forms which consist of more than one word yet which are not syntactically the same as compounds. One familiar type of fixed form is the idiom. Let us take the idiom 'to bite the dust' meaning 'to die'. It is fixed, like a fossilized chunk of language, insomuch as what the speaker can do with it is limited. We can say 'he bit the dust', but not (without producing a highly marked utterance) 'I think he deserves a dust-biting': we cannot say 'he chewed the dust' or 'he bit some dust' without radically changing the meaning of the idiom. Its 'idiomaticity' is partly identified by its fixedness; there is no sensible way in which this fossilized block can be carved up into smaller pieces for language teaching; it should clearly be treated just like basic roots, derived words, and compounds, that is to say, as a single lexical item even though, in its internal structure, it is a clause, with a verb and an object. All languages are rich in idioms and specialized idiom dictionaries are available (e.g. for English, Cowie and Mackin 1975; Cowie, Mackin, and McCaig 1983; Longman 1979). Idioms can often be grouped together according to form (Cowie and Mackin 1975, brings together verbs and particles). In English, one recurring type is the verb+ the + object idiom, as in:

to bite the dust

to kick the bucket

to pass the buck

Certain verbs seem to be 'idiom-prone' and regularly partake in theformation of idioms, for example, as with 'go' and 'make':

to go mad to make the best of

to go west to make money

to go off to make something of

to go wild to make off with

to go easy to make something up

\section{REFERENCES}

[1] Alanen, R. (2003). A sociocultural approach to young language learners' beliefs about language learning. In P. Kalaja\& A. M. F. Barcelos (Eds.), Beliefs about SLA:New Research Approaches (pp. 55-87). Dordrecht: Kluwer.

[2] Abraham, R., \& Vann, R. (1987). Strategies of two language learners: A case study. In A. Wenden\& J. Rubin (Eds.), Learner Strategies in Language Learning (pp. 85- 102). Englewood Cliffs, NJ: PrenticeHall.

[3] Ahour, T., \&Salamzadeh, P. (2014).Vocabulary learning strategies used by poor Iranian high school students.International Journal of Language Teaching and Research,2, 12-15.

[4] Al-Handhali, H. K. (2009). Learners' beliefs about listening in an Omani secondary school.In M. Wyatt \& J. Atkins (Eds.), Research perspectives on education inOman (pp. 137-152).Ministry of education, Sultanate of Oman.

[5] Anderson, J. (1983). A spreading activation theory of memory.Journal of VerbalLearning and Verbal Behavior, 22, 261-295.

[6] Arden-Close, C. (1993). NNS readers' strategies for inferring the meaning of unknownwords.Reading in a Foreign Language, 9, 867-893.

[7] Atkinson, R., \&Raugh, M. (1975).An application of the mnemonic keyword method tothe acquisition of a Russian vocabulary.Journal of Experimental Psychology:Human Learning and Memory, 1, 126-133. 
[8] Atkinson \& Shiffrin, 1968.

[9] Ayatollahi, M, Rasekh, A \& Tavakoli, M. (2012). Learner beliefs, self-regulated learningstrategies and L2 academic reading comprehension: A structural equationmodeling analysis. World Applied Sciences Journal, 17, 36-49.

[10] Bakhtin, M. (1981).The dialogic imagination: Four essays. University of Texas Press.

[11] Barcelos, A. M. F. (1995). A cultura de aprnder lingua estrangeira (inglês) de alunos deLetras [The culture of learning a foreign language (English) of language students].Unpublished Master's Thesis, UNICAMP, San Paolo, Brasil.

[12] Barcelos, A. M. F. (2003). Researching beliefs about SLA: a critical review. In P. Kalaja\& A. M. F. Barcelos (Eds.), Beliefs about SLA: New Research Approaches (pp. 7-35). Dordrecht: Kluwer.

[13] Barcelos, A. M. F. (2003). Teachers' and students' beliefs within a Deweyan framework:Conflict and influence. In P. Kalaja\& A. M. F. Barcelos (Eds.), Beliefs aboutSLA: New Research Approaches (pp. 171201). Dordrecht: Kluwer.

[14] Dakun, W., \&Gieve, S. (2008).Learning environment and the use of vocabulary learning strategies: A case study of Chinese learners.Indonesian Journal of EnglishLanguage Teaching, 4, 56-87.

[15] Deng, K. (2009). Rethinking error feedback on L2 writing.JALT 2009 conference proceedings, p. 579609.

[16] Devine, J. (1988). A case study of two readers: Models of reading and reading performance. In P. L. Carrell, J. Devine, \& D. Eskey (Eds.), Interactive approaches to second language reading (pp. 127-139). Cambridge: Cambridge University Press.

[17] Donato, R., \& McCormick, D. (1994). A sociocultural perspective on language learning strategies: the role of mediation. The Modern Language Journal, 78, 453-464.

[18] Dörnyei, Z. (2001). Teaching and researching motivation. Harlow: Pearson Education Limited

[19] Ehrman, M., Leaver, B, \& Oxford, R. (2003).A brief overview of individual differences in second language learning, System. 31, 313-330.

[20] Elgort, I. (2011). Deliberate learning and vocabulary acquisition in a second language.Language Learning, $61,367-413$.

[21] Ellis, N. C. (1995). The cognitive psychology of foreign language vocabulary learning.The Language Teacher, 19, 12-16.

[22] Ellis, N. C. (1996). Sequencing in SLA: Phonological Memory, Chunking and Points of Order. Studies in Second Language Acquisition, 18, 91-126.

[23] Fan, M (2003). Frequency of use, perceived usefulness, and actual usefulness of second language vocabulary strategies: A study of Hong Kong learners. The ModernLanguage Journal, 87, 222-241.

[24] Ferris, D. (1995). Student reactions to teacher response in multiple-draft composition classrooms.TESOL Quarterly, 29, 33-53.

[25] Ferris, D. (1997). The influence of teacher commentary on student revision.TESOL Quarterly, 31, 315339.

[26] Folse, K. (2004). Vocabulary myths: Applying second language research to classroom teaching. Ann Arbor: University of Michigan Press.

[27] Fraser, C. (1999a). The role of consulting a dictionary in reading and vocabulary learning. The Canadian Journal of Applied Linguistics, 2, 73-90.

\section{AUTHOR'S BIOGRAPHY}

Ms. Manal is a lecturer at the Department of English, College of Education, Gedarif University, Sudan. She is recently working for the Department of English, College of Science and Humanities, Prince Sattam University, KSA. Currently she is a Ph.D candidate at College of Languages, Sudan University of Science and Technology. Ms. Manal obtained her bachelor degree in English from Omdurman Islamic University, College of Arts in 1996. She received her Post-Graduate Diploma in English Language Teaching in 2000 from Khartoum University, College of Education and her master degree in linguistics in 2001 from the same university and college. Ms. Manal areas of interest include Computer Assisted Language Learning (CALL), E-learning and English Language Teaching (ELT).

Citation: ManalAwad Mohammed Elwakeil. "Call and Vocabulary Acquisition (Theoretical Perspective)". International Journal on Studies in English Language and Literature (IJSELL), vol 5, no. 10, 2017, pp. 68-73. doi:http://dx.doi.org/10.20431/2347-3134.0510009.

Copyright: (C) 2017 Authors. This is an open-access article distributed under the terms of the Creative Commons Attribution License, which permits unrestricted use, distribution, and reproduction in any medium, provided the original author and source are credited. 